\title{
The vista paradox: A natural visual illusion
}

\author{
JAMES T. WALKER, RETA C. RUPICH, and JACK L. POWELL \\ University of Missouri-St. Louis, St. Louis, Missouri
}

\begin{abstract}
Suppose an observer views a distant object through a window in the far wall of a room or corridor-a visual scene consituting a vista. If the observer moves toward the window, then the distant object will shrink in apparent size and appear farther away. These effects are paradoxical, because the distant object appears smaller as its visual angle increases. The vista paradox occurs under many other real-world conditions, such as viewing a distant object while moving out of the mouth of a valley, or driving across a topographic crest. In the present study, framing effects and the equidistance tendency are considered as possible factors. However, an explanation based on the dynamic relationship between the visual angle of the framing portion of a vista and the visual angle of a distant object appears more promising.
\end{abstract}

A vista is a view or prospect, especially one seen through a long, narrow avenue or passage (Random House Dictionary, 1983). For example, consider a vista encompassing a distant object seen through a window at the far end of a long corridor. As the observer approaches the window, the apparent size of the distant object shrinks greatly, in some cases by a factor of two or more, and the apparent distance to the object increases. These effects are paradoxical, since the distant object shrinks in apparent size as its visual angle increases, and the object appears farther away as the observer moves closer. The term vista paradox will here be applied to these apparent size and distance effects.

The vista paradox appears most striking where the view of a distant object is rather closely surrounded by an aperture, such as a window-or a frame, notch, or the mouth of a natural valley-and where the object is many times farther away than the maximum distance between the observer and the aperture. For example, at the St. Louis Convention Center, a large window at the end of a 55-m hallway provides a view of a bridge across the Mississippi River about $930 \mathrm{~m}$ from the window. At the maximum viewing distance, the horizontal and vertical dimensions of the bridge subtend visual angles of $4.5^{\circ}$ and $2^{\circ}$, while the same dimensions of the window subtend $9^{\circ}$ and $4.5^{\circ}$. As the observer approaches the window, the bridge shrinks dramatically in apparent size and appears farther away.

In the above situation, as the observer moves toward the window, the visual angle of the distant bridge increases

This paper has profited greatly from discussions with several people before and after an oral presentation at the annual meeting of the Psychonomic Society in Minneapolis, MN, November 11, 1982. We are grateful to Daniel J. Weintraub and Stanley Coren for bringing some relevant literature to our attention, and to William $R$. Uttal for describing his own observation of the vista paradox. Address reprint requests to James T. Walker, Department of Psychology, University of Missouri-St. Louis, St. Louis, MO 63121. Jack L. Powell is now affiliated with the University of Hartford, Hartford, CT. very little-about $16^{\prime}$ horizontally and $7^{\prime}$ vertically, as measured in photographs-while the visual angle of the window increases by many times, to nearly $180^{\circ}$. Thus, as an observer approaches an aperture, the size of its visual image increases more rapidly than that of a more distant object viewed through it. The resulting size contrast and other factors that may contribute to the vista paradox will be discussed in later sections.

The vista paradox is readily observable over a wide range of viewing distances, under many conditions. A distant object seen through a highway underpass shrinks in apparent size and appears farther away as the observer drives through the underpass. In driving across a suspension bridge - the Tacoma Narrows Bridge over Puget Sound, for example-a distant tower of the bridge seen through the opening in a nearer tower shrinks in apparent size as the observer passes through the opening. Chinaman's Hat, a small island off the Oahu shore, shrinks greatly in apparent size as the observer drives through the mouth of a valley affording a vista of the island (Uttal, personal communication, 1982).

These observations of the vista paradox are closely comparable to the coffee cup illusion described by Senders (1966). Suppose an observer views the reflection of an overhead light in a cup of coffee, holding the head at such a distance that the image of the light nearly fills the cup. If the observer then moves the head rapidly and smoothly toward the surface of the coffee, the apparent size of the light decreases greatly, and its apparent distance increases. The effect also occurs in a small mirror, which offers the advantage of a more stable reflecting surface.

In the present experiments, we investigated the vista paradox in a convenient real-world setting, utilizing a small window offering a view of 3 distant flagpoles. Experiment 1 was designed to demonstrate the vista paradox in this setting. Experiment 2 included an adjustment procedure to indicate the change in apparent height of the flagpoles. In Experiments 3 and 4, the subjects made numerical estimates of the changes, respectively, in the apparent size and distance of the flagpoles. Experiment 5 
included an adjustment procedure to measure changes in apparent distance.

\section{EXPERIMENT 1}

\section{Method}

Subjects. Ten faculty members and graduate students in the Department of Psychology, University of Missouri at St. Louis, served as subjects. All were naive with regard to the purpose of the experiment.

The visual scene. Three flagpoles, $11 \mathrm{~m}$ tall and $3.7 \mathrm{~m}$ apart, were located $65.5 \mathrm{~m}$ from a window with a single pane of clear glass, which measured $52 \times 61 \mathrm{~cm}$ horizontally and vertically. The window was on the second floor, approximately level with the center of the flagpoles. The flagpoles were located near a 3-story building and were seen against a background of trees and distant buildings. At the maximum viewing distance, the subjects were $3.5 \mathrm{~m}$ from the window, and at the minimum distance they were nearly touching the glass.

At the maximum viewing distance, the array of flagpoles subtended visual angles of $6.1^{\circ}$ and $9.1^{\circ}$ horizontally and vertically, and at the minimum distance, these visual angles were $6.5^{\circ}$ and $9.6^{\circ}$. The window subtended $8.5^{\circ}$ and $10.1^{\circ}$ horizontally and vertically at the distance of $3.5 \mathrm{~m}$. At the minimum distance, the horizontal subtense of the window approached $180^{\circ}$, and the vertical angle of view was limited only by the subject's facial anatomy. Thus, at the farthest viewing distance the flagpoles were closely framed by the window, and at the nearest distance, the sides of the window were in the far periphery of the visual field.

Procedure. Each subject stood $3.5 \mathrm{~m}$ from the window. The subject was instructed to note the apparent height of the flagpoles, and to walk briskly toward the window while observing the flagpoles, paying attention to any change in their apparent height. After reaching the window, the subject indicated whether the flagpoles appeared taller or shorter. Most subjects made their judgments readily after a single trial, but a few required a second trip to the window.

\section{Results and Discussion}

All 10 subjects reported that the flagpoles appeared shorter as they approached the window $(Z=2.85$, $p<.01$ ). The effect appeared compelling to most of the subjects, although it was more subtle for others. Some subjects volunteered the observation that the flagpoles also appeared farther away as they approached the window.

\section{EXPERIMENT 2}

Experiment 2 was designed to provide quantitative measures of the vista paradox. In pilot observations, we asked the subjects to estimate the flagpoles' height and distance in feet, as seen from the greater viewing distance and also from the nearer distance directly in front of the window. These judgments were erratic, and they were difficult and disagreeable for the subjects to make, consistent with other observations of absolute size and distance judgments (see e.g., Over, 1963). Thus, we devised an adjustment procedure to measure the change in apparent height of the flagpoles as the subjects walked toward the window.

\section{Method}

Subjects. Ten introductory psychology students at the University of Missouri at St. Louis received extra course credit for their participation.

Apparatus and Procedure. The same visual scene, viewing conditions, and distances as in Experiment 1 were used. The same procedures were used here too, with the addition of the adjustment procedure described below. Each subject approached the window, noting any change in the apparent height of the flagpoles. The subject then adjusted a vertical comparison line to indicate the change in apparent height.

The comparison line was projected on a white screen by means of a slit in the focal plane of a slide projector. An iris diaphragm in the focal plane allowed the subject to adjust the length of the line by turning a knob. The screen measured $71 \times 112 \mathrm{~cm}$ horizontally and vertically, and was located about $2 \mathrm{~m}$ from the subject, $90^{\circ}$ to the right of the line of sight to the flagpoles. Thus, it was not possible to see the flagpoles and the comparison line at the same time. The comparison line, $24 \mathrm{~mm}$ thick, was initially set to a height of $50.5 \mathrm{~cm}$, subtending a visual angle of about $14.5^{\circ}$. The subjects were instructed to let the initial length of the line represent the size of the flagpoles as they appeared from the farther viewing distance, and to adjust the line to indicate any change in apparent size as the subjects approached the window. Each subject made a single adjustment of the comparison line.

\section{Results and Discussion}

Nine of the 10 subjects reported that the flagpoles appeared smaller as they approached the window, and 1 subject reported that they appeared larger. Adjustments ranged from 27.5 to $60.0 \mathrm{~cm}$, representing, respectively, a decrease of $23.0 \mathrm{~cm}$ and an increase of $9.5 \mathrm{~cm}$ in the height of the $50.5-\mathrm{cm}$ comparison line. The mean adjustment was $39.50 \mathrm{~cm}$, and the standard deviation was $9.46 \mathrm{~cm}$, representing an apparent shortening of $21.76 \%$. The mean adjustment differed significantly from $50.5 \mathrm{~cm}$ $[t(9)=3.68, p<.01]$.

The present results were consistent with the results of Experiment 1. Thus, two different judgment procedures indicated that the flagpoles shrank in apparent size as the observers approached the window.

\section{EXPERIMENT 3}

In Experiment 3, the subjects made numerical estimates of the changes in feet in the apparent height of the flagpoles as they approached the window. We expected these relative judgments to be easier and more reliable than the absolute judgments we had previously asked the pilot subjects to make.

\section{Method}

Subjects. Eleven introductory psychology students served as the subjects.

Procedure. The procedures were fundamentally the same as in Experiments 1 and 2, except here, the subjects estimated in feet the amount of any change in the apparent height of the flagpoles as they walked toward the window. Most of the subjects made these judgments readily after a single approach to the window, although a few required a second trial. 


\section{Results and Discussion}

All of the subjects indicated that the flagpoles appeared shorter as they approached the window. Estimates of the decrease in apparent size ranged from 2 to $25 \mathrm{ft}$. The mean apparent decrease was $13.82 \mathrm{ft}(4.21 \mathrm{~m})$, and the standard deviation was $7.18 \mathrm{ft}(2.19 \mathrm{~m})$. Thus, the mean apparent decrease differed significantly from zero $[t(10)=$ $6.38, p<.001]$. In relation to the objective height of the flagpoles, $36 \mathrm{ft}(11 \mathrm{~m})$, the mean apparent decrease represents a change of $38.39 \%$.

These findings were consistent with the results of Experiments 1 and 2 . Thus, three different judgment procedures-categorical judgments of "larger"' or "smaller," size adjustments, and numerical estimates of changes in apparent size-yielded consistent indications of the size effect in the vista paradox.

\section{EXPERIMENT 4}

In Experiment 4, the subjects estimated the change in the apparent distance of the flagpoles in feet as they approached the window.

\section{Method}

Subjects. Nineteen introductory psychology students served as the subjects.

Procedure. The subjects stood $3.5 \mathrm{~m}$ from the window. They were instructed to note the apparent distance to the flagpoles, and to walk briskly toward the window, paying attention to any change in the apparent distance of the flagpoles. The subjects then indicated whether the flagpoles looked closer or farther away as they approached the window, and estimated in feet the change in the apparent distance. These egocentric judgments of apparent distance were more difficult than the estimations of changes in apparent height in Experiment 3.

\section{Results and Discussion}

Estimates of the change in apparent distance ranged from an increase of $110 \mathrm{ft}(33.52 \mathrm{~m})$ to a decrease of $50 \mathrm{ft}$ $(15.24 \mathrm{~m})$. The mean change in apparent distance was an increase of $13.47 \mathrm{ft}(4.11 \mathrm{~m})$, and the standard deviation was $35.72 \mathrm{ft}(10.89 \mathrm{~m})$. This mean was not significantly different from zero $[t(18)=1.64]$.

As an observer walks toward a distant object, its egocentric distance decreases. Under most conditions in the real world, as we approach a stationary object, its apparent distance decreases monotonically with the decreasing objective distance. But if an object looks farther away to an approaching observer, as in the vista paradox, then there is a conflict between the way things look and the way things are. Some observers may resolve such a perceptual-cognitive conflict in favor of perception, and others in favor of cognition. It may be that the egocentric estimates of apparent distance in the present experiment increased the likelihood of perceptual-cognitive conflicts.

The conflict argument above might also be applied to the size effect in the vista paradox - and indeed, to many other illusions in general. As the observer approaches a stationary object, its visual angle increases, and so does the size of its retinal image. Now if the apparent size of the object decreases, as in the vista paradox, there may be a perceptual-cognitive conflict here too, to the extent that subjects are aware of the relationship between decreasing distance and increasing visual angle. But that relationship is much less immediate than the usual relationship between decreasing objective and decreasing apparent distance. Thus, we should expect greater perceptual-cognitive conflicts in distance judgments than in size judgments in the vista paradox. To minimize these conflicts, the apparent distance of the flagpoles from the window was measured by means of an adjustment procedure in the next experiment.

\section{EXPERIMENT 5}

In view of the failure of the distance estimation procedure in Experiment 4, the instructions to the subjects were modified, and an adjustment procedure was used in Experiment 5 to measure the increase in apparent distance observed in the vista paradox.

\section{Method}

Subjects. Fifteen introductory psychology students participated in Experiment 5.

Apparatus and Procedure. Except as noted, the same procedures as in the previous experiments were followed. In the present experiment, the subjects were instructed to indicate any change in the apparent distance of the flagpoles from the window. These instructions were intended to direct the subjects' attention to any change in the apparent distance of the flagpoles from the window, as opposed to the objective decrease in their egocentric distance as measured from the point of view of an approaching observer.

After reaching the window, the subject indicated whether the flagpoles looked closer to the window or farther away than they had looked from the starting position. The subject then adjusted the location of the model flagpoles in the apparatus (see Figure 1), to indicate any change in the apparent distance of the flagpoles from the window.

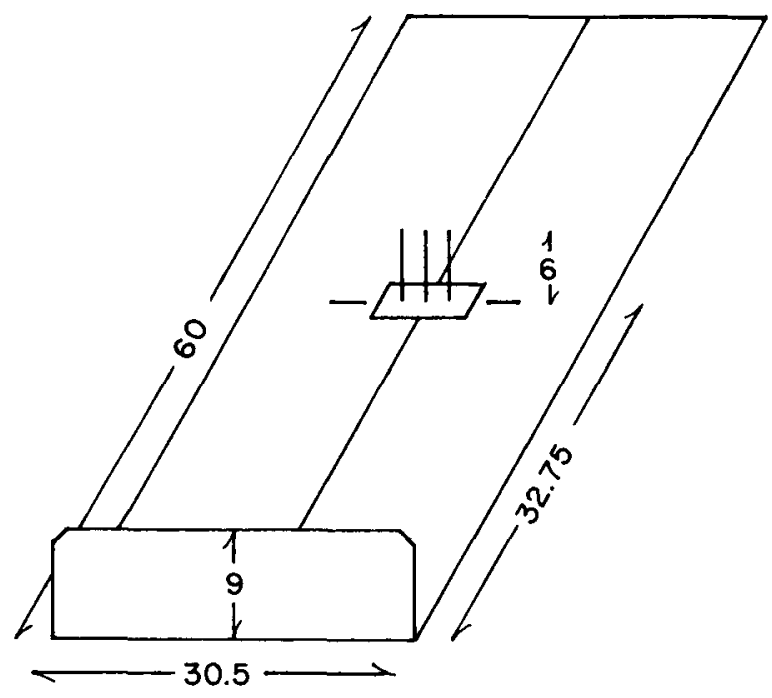

Figure 1. Scale model of flagpoles (1/200) used in Experiment 5 (dimensions in centimeters). 
The apparatus was a model representing the essential features of the visual scene on a scale of 1:200. The model was placed beside the window, with its far end against the wall and its horizontal surface $130 \mathrm{~cm}$ above the floor. It was not possible for one to see the real flagpoles while adjusting the model.

The floor of the model was smooth wood, stained light brown, and the front was brown Masonite. The model flagpoles were made out of brass wire $1 / 16 \mathrm{in}$. $(1.59 \mathrm{~mm})$ in diameter, mounted in a Plexiglas carrier that rode in a narrow groove. The model flagpoles were presented at a distance of $32.75 \mathrm{~cm}$ from the front of the apparatus, representing the $65.5-\mathrm{m}$ distances of the real flagpoles from the actual window. The initial location of the model flagpoles was marked by prominent index lines, which remained in place as the subjects adjusted the apparatus.

Each subject was instructed to let the initial distance between the model flagpoles and the front of the apparatus represent the apparent distance of the real flagpoles from the window, as seen from the farther viewing position. The subject stood in front of the apparatus and moved the model flagpoles to indicate any change in their apparent distance as the subject approached the window. Each subject made a single adjustment.

\section{Results and Discussion}

All of the subjects indicated that the flagpoles appeared farther away as they approached the window. Increases in the adjusted distances of the model flagpoles ranged from 4.1 to $22 \mathrm{~cm}$, the largest movement possible in the apparatus. The mean increase was $10.69 \mathrm{~cm}$, and the standard deviation was 5.69. The mean differed significantly from zero $[t(13)=7.02, p<.001]$. In relation to the initial distance of the model flagpoles from the front of the apparatus, $32.75 \mathrm{~cm}$, the mean increase represents a change of $32.63 \%$.

The instructions in Experiment 5 were nonegocentric, emphasizing that the subjects were to judge any change in the apparent distance of the flagpoles from the window, as opposed to the egocentric instructions in Experiment 4 . In addition, the present experiment used an adjustment method, as opposed to the numerical estimates of changes in apparent distance in Experiment 4. These procedural differences, either one or both, resulted in the significant distance effect observed in Experiment 5.

\section{GENERAL DISCUSSION}

Table 1 shows the means and standard deviations of the changes in apparent size and distance in Experiments 2 through 5, where quantitative estimates or adjustments were made. To facilitate comparisons, the data in this table are shown in terms of percentage decreases in apparent size and increases in apparent distance. Considering

\section{Table 1}

Changes in Apparent Size and Distance Where Quantitative Estimates or Adjustments Were Made (Means and Standard Deviations in Percent)

\begin{tabular}{lcrc}
\hline & $N$ & $M$ & $S D$ \\
\hline Experiment 2: Height adjustments & 10 & 21.76 & 18.71 \\
Experiment 3: Height estimates & 11 & 38.39 & 19.95 \\
Experiment 4: Distance estimates & 19 & 6.27 & 16.63 \\
Experiment 5: Distance adjustments & 15 & 32.63 & 17.40 \\
\hline
\end{tabular}

the widely differing measurement procedures in these experiments, these measures are remarkably comparable in variability, as their standard deviations indicate.

A simple analysis of variance found a significant effect of experiments $[F(3,51)=9.71, p<.001]$. As we noted earlier, the mean of the numerical distance estimates in Experiment 4 was not significantly different from zero, but all of the other means were. By Newman-Keuls tests, the mean of Experiment 4 differed from each of the other means $(p<.05)$, but there were no significant differences among the means of Experiments 2, 5, and 3.

In the coffee cup illusion, Senders reported a decrease in apparent size of 75 or $80 \%$, whereas our size effects were 21.76 and $38.39 \%$ in Experiments 2 and 3. Senders also reported that the apparent distance to the light increased about 10 times as much as the observer's movement toward the coffee cup. Our increase in apparent distance in Experiment 5 was $32.63 \%$ of the distance from the window to the flagpoles. Since that distance was $65.5 \mathrm{~m}$, our results represent an increase of $21.37 \mathrm{~m}$ in apparent distance as the subjects moved $3.5 \mathrm{~m}$ in approaching the window. Thus, our increase in apparent distance was 6.11 times the subjects' movement. Although we have limited confidence in the precision of these meaures, the rough agreement between our results and Senders' is somewhat reassuring.

Framing effects may contribute to the vista paradox. A line enclosed in a frame, or flanked by other lines, looks larger under some conditions than an unenclosed comparison line (Brigell, Uhlarik, \& Goldhorn, 1977; Fellows, 1968; Künnapas, 1955; Weintraub \& Schneck, 1986; Weintraub, Wilson, Greene, \& Palmquist, 1969). The effect is maximal at a framing ratio of about $2: 1$ or less-that is, when the frame is about twice as long as the enclosed line. At higher framing ratios, the effect decreases and may eventually reverse. Thus, a distant object closely framed by an aperture should appear larger. Frame-of-reference effects have also been considered as possible explanations of the moon illusion (see e.g., Baird, 1982; Restle, 1970, 1971).

A pilot of an airliner, seated about $1 \mathrm{~m}$ from the windshield, tends to see another airplane as farther away and less threatening than does an observer seated about $2 \mathrm{~m}$ from the windshield immediately behind the pilot (Kraft, Farrell, \& Boucek, 1970). From the farther position, the windshield frames the other airplane more closely, making it appear larger, nearer, and more threatening. In laboratory simulations, experienced pilots have consistently been subject to the effects of these viewing positions. Roscoe (1980) has suggested that these effects are due to accommodation to the frame of the windshied seen from the farther position, resulting in the minification of the visual image and an increase in the apparent distance of another airplane. Similar size and distance effects, whatever their origin, may also occur in automobiles, where traffic and other hazards sometimes appear more frightening to a passenger in the back seat than to the driver. 
Although framing effects may be at work in the vista paradox, they cannot be the sole factor. The size and distance effects are less compelling in pictures, even though real-world framing ratios can be reproduced faithfully. Even in the real world, these effects are much reduced-or sometimes nonexistent-if the observer views the scene from a succession of fixed positions without experiencing the dynamically changing visual angles of the aperture and of distant objects. Senders (1966) considered these dynamic relationships (further discussed below) crucial in the coffee cup illusion, noting that observation from any fixed point abolished the illusion.

According to the equidistance tendency, objects that are separated in depth tend to be seen at the same distance from the observer, particularly under reduced viewing conditions (Gogel, 1965a; Judd, 1898). The adjacency principle holds that the equidistance tendency is stronger for objects that are more nearly visually adjacent-that is, closer in terms of visual direction (Gogel, 1965b).

For viewing a distant object closely framed by an aperture, the equidistance tendency predicts that the object and aperture will tend to be seen at the same distance. To the approaching observer, the edges of the aperture move away from the distant object, decreasing the directional adjacency between the object and the aperture, weakening the equidistance tendency, and making the distant object look farther away.

However, a problem arises when one attempts to extend the equidistance tendency to the observed decrease in apparent size. If an object subtending a constant visual angle is somehow made to appear farther away, then the object must appear larger, through the operation of size constancy and Emmert's law (Boring, 1940; Epstein, Park, \& Casey, 1961). Now, as the observer approaches the aperture, if the weakening of the equidistance tendency causes the distant object to look farther away, then its apparent size should increase. Thus, the equidistance tendency cannot explain the decrease in apparent size in the vista paradox.

For an approaching observer, the visual angle of a distant object increases slightly while the visual angle of the aperture increases greatly. As a result of this dynamic relationship, the visual angle of the object is a decreasing fraction of the visual angle of the aperture.

At the far viewing distance, where an aperture closely frames an object, its apparent size and distance are somewhat indeterminate because much of the surrounding area is occluded. Under roughly comparable reduced-viewing conditions in size-constancy experiments, smaller visual angles result in smaller apparent size and greater apparent distance (see e.g., Epstein \& Landauer, 1969; Holway \& Boring, 1949). Now in the vista paradox, if the dynamic decrease in the ratio of the visual angle of the object to that of the aperture were to result in an apparent decrease in the visual angle of the distant object-or in some other decrease in the effective size of the image- then the object might shrink in apparent size and look farther away. Such a possibility is of course highly speculative in the absence of supporting evidence, although it seems clear that dynamic factors are at work in the vista paradox.

In addition to the real-world observations already described, the vista paradox occurs under other conditions. For example, in driving toward a crest on a highway, suppose a more distant object comes into view. As the driver approaches the crest, the distant object shrinks in apparent size and appears farther away. In this situation, a topographic crest has some of the properties of the edge of an aperture.

When fighter pilots fly terrain-avoidance maneuvers at low altitudes and high speeds, they often pass through valleys and over ridges in rugged areas. Under these conditions, misperceptions of the size and distance of environmental features can have disastrous consequences. Thus, the vista paradox may be of some concern in high-speed terrain-avoidance flight, where size and distance judgments are critical.

\section{REFERENCES}

BAIRD, J. C. (1982). The moon illusion: II. A reference theory. Journal of Experimental Psychology: General, 111, 304-315.

BorING, E. G. (1940). Size constancy and Emmert's law. American Journal of Psychology, 53, 293-295.

Brigell, M., Uhlarik, J., \& Goldhorn, P. (1977). Contextual influences on judgments of linear extent. Journal of Experimental Psychology: Human Perception \& Performance, 3, $105-118$.

EPSTEIN, W., \& LANDAUER, A. A. (1969). Size and distance judgments under reduced conditions of viewing. Perception \& Psychophysics, 6, 269-272.

Epstein, W., Park, J., C CASEY, A. (1961). The current status of the size-distance hypothesis. Psychological Bulletin, 58, 491-514.

Fel.Lows, B. J. (1968). The reverse Müller-Lyer illusion and 'enclosure.' British Journal of Psychology, 59, 369-372.

GoGEL, W. C. (1965a). Equidistance tendency and its consequences. Psychological Bulletin, 64, 153-163.

GoGEL, W. C. (1965b). Size cues and the adjacency principle. Journal of Experimental Psychology, 70, 289-293.

Holway, A. H., \& Boring, E. G. (1941). Determinants of apparent visual size with distance variant. American Journal of Psychology, 54, 21-37.

Judd, C. H. (1898). An optical illusion. Psychological Review, 5, 286-294.

Kraft, C. L., FArrell, R. J., \&oucek, G. P. (1970). Visual performance from the $737 \mathrm{cab}$ as a function of pilots' position within the cab. Unpublished technical report, The Boeing Co., Seattle, WA.

KüNNAPAs, T. M. (1955). Influence of frame size on apparent length of line. Joumal of Experimental Psychology, 50, 168-170.

OVER, R. (1963). Size and distance-estimates of a single stimulus under different viewing conditions. American Journal of Psychology, 76, 452-457.

Random House Dictionary. (1983). New York: Random House. RESTLE, F. (1970). Moon illusion explained on the basis of relative size Science, 167, 1092-1096.

RestLe, F. (1971). Visual illusions. In M. H. Appley (Ed.), Adaptationlevel theory: A symposium (pp. 55-69). New York: Academic Press. Roscoe, S. N. (1980). Visual judgments of size and distance. In S. N. Roscoe (Ed.), Aviation psychology (pp. 97-107). Ames, IA: Iowa State University Press. 
SEnders, J. W. (1966). The coffee cup illusion. American Journal of Psychology, 79, 143-145.

Weintraub, D. J., \& Schneck, M. K. (1986). Fragments of Delbouef and Ebbinghaus illusions: Contour/context explorations of misjudged circle size. Perception \& Psychophysics, 40, 147-158.

Weintraub, D. J., Wilson, B. A., Greene, R. D., \& Palmquist,
M. J. (1969). Delbouef illusion: Displacement versus diameter, arc deletions, and brightness contrast. Journal of Experimental Psychology, 80, 505-511.

(Manuscript received March 7, 1988;

revision accepted for publication June 20,1988 .) 